\title{
Design and modelation of piping systems by means of use friction factor in the transition turbulent zone
}

\author{
Yanán C. Medina ${ }^{1 *}$, Oscar M.C. Fonticiella ${ }^{1}$, Osvaldo F.G. Morales ${ }^{2}$ \\ Center for Energy Studies and Environmental Technologies, Universidad Central de las Villas, \\ Santa Clara, Cuba \\ Technical Sciences Faculty, Universidad de Matanzas, Matanzas, Cuba
}

Email: ycamaraza1980@yahoo.com

\begin{abstract}
In this paper a new model is presented for design and modelation of piping systems. This work results from recent investigations on pipes friction factor. It provides an empirical solution for the solution of the three basic problems found in the design and evaluation of pipe systems, which in conventional cases require tedious iterative trial and error processes. The proposed solutions are valid in the same interval as the traditional methods used, and in all cases the average error computed never exceeds $2 \%$ with respect to traditional iterative methods. The research was done with a regression analysis between kinematic viscosity, relative roughness, flow rate, friction factor, and others factor, using experimental data reported by different authors, establishing comparison with the Swamee-Jain solution for this problems types concluding that between new model and the most universally used there are not signified differences without is lightly better.
\end{abstract}

Keywords: Explicit Equation, Darcy Friction Factor, Flow in Pipes, Pipe Diameter.

\section{INTRODUCTION}

Many of the current problems of engineering involve the flow of fluids in pipes, this brings associated that the determination of the friction factor in these systems is of vital importance for an adequate study of the process in question. Friction is an element that occurs in any flow regime, either in single phase or in two phases. For the determination of Darcy's friction factor, one of the most widespread works in the world is the wellknown Coolebrook-White Equation, which in a simplified form is described by the following expression:

$$
\frac{1}{\sqrt{f}}=-2 \log \left(\frac{e / d}{3.7}+\frac{2,51}{\operatorname{Re} \sqrt{f}}\right)
$$

In Equation (1) $e$ is the pipe wall equivalent sand grain roughness, $d$ Equivalent inner tube diameter of pipe, $f$ in the Darcy-Weibach dimensionless friction factor; $\operatorname{Re}=G d / \mu$ is the Reynolds number, (with $G$ being the mass flux and $\mu$ the dynamic viscosity).

However it is known and confirmed at the same time by experiments, than at the totally wrinkled zone the numerical value of Reynolds's dimensionless number stops influencing the friction factor, depending on relative roughness of the numerical value of Reynolds's dimensionless number, the one that the friction factor begins to be persevering may be determined by the following expression obtained by (Camaraza: 2011)

$$
\operatorname{Re}_{C R I T 2} \approx \frac{542,38}{(e / d)^{1,13}}
$$

Table 1. Equivalent roughness values for new commercial pipes

\begin{tabular}{|c|c|}
\hline Material & Roughness $\boldsymbol{e} \mathbf{( m m )}$ \\
\hline Glass , plastic & $0,0005-0,01$ \\
\hline Concrete & $0,05-9$ \\
\hline Wood stave & 0,5 \\
\hline Rubber smoothed & $0,01-0,06$ \\
\hline Commercial steel & $0,04-0,08$ \\
\hline Cooper or brass tubing & $0,01-0,05$ \\
\hline Cast iron & $0,15-0,35$ \\
\hline Galvanized iron & $0,07-0,23$ \\
\hline Wrought Iron & $0,025-0,046$ \\
\hline Stainless steel & $0,002-0,004$ \\
\hline
\end{tabular}

The absolute roughness value $e$, included in the above Equations, varies with the material of the conduit and with the 
technology of its manufacture. In this paper, the values recommended in the Cuban's NC-176-2002 are shown in the table 1

The tubes used in industrial facilities are different from those used in the experiments in the sense that the roughness of the former is not uniform and it is difficult to give an accurate description of it. Table 1 gives values of the equivalent roughness for some commercial pipes, but it must be borne in mind that these values are for new pipes and the relative roughness of these can be increased with the use as a consequence of corrosion, the accumulation of scale. and the precipitation. As a result, the friction factor can be increased by a factor of 5 to 10

It is worth mentioning that the precision of the calculations on friction in the tubes, can vary with the somewhat unpredictable change in the roughness and the friction factor, due to the accumulation of sediment and corrosion on the walls of the tube with the time of use of the conduit. This accumulation not only increases the surface roughness, but also reduces the effective diameter of the tube and can lead to a potentially large increase in the friction factor after the tube has been in service for a long period, so in these cases the roughness values given in the table can contain errors that can compute up to $70 \%$.

In the literature consulted a remarkable group of explicit Equations for the calculation of the Darcy friction factor $f$ in smooth and rough pipes for turbulent regime. For the determination of the pressure losses in pipes or systems of these, it is required to estimate the friction factor. To this end, iterative solutions such as Equation (1) can be used, however their use requires an appreciable calculation time, especially when studying large water distribution networks. A quick solution that currently enjoys great acceptance is the use of the Moody diagram, especially in previous decades, however its use has two important drawbacks:

1- The precision of the results is affected by reading errors in logarithmic scale

2 - it is not possible to apply in computer-aided simulations

In the design and analysis of piping systems that involve the use of the Moody chart (or the Colebrook Equation), is it usually encounter three types of problems, in which the fluid and the roughness of the pipe are assumed to be specified in all cases. I) Determining the pressure drop (or head loss) when the pipe length and diameter are given for a specified flow rate (or velocity); II) Determining the flow rate when the pipe length and diameter are given for a specified pressure drop (or head loss) and III) determining the pipe diameter when the pipe length and flow rate are given for a specified pressure drop (or head loss)

In the engineering processes that require the analysis of piping systems, there are generally three basic types of problems to be solved, in which it is necessary to assume the specific pipe roughness. These three basic problems are reduced to: I. Determine the pressure drop for the circulation of a required flow (or velocity), the diameter and length of the pipe being known.

II. Determine the allowable flow rate for a preset pressure drop, the diameter and length of the pipe being known.

III. Determine the diameter of the pipe required for a preset pressure drop, the length of the pipe and the flow rate flowing through it being known.

\section{MATERIALS AND METHODS}

\subsection{Development of problems type I.}

The problem type $\mathrm{I}$ is the simplest of all because the results sought are obtained directly. The friction factor is determined and then the Darcy Weibash relationship is implemented to obtain the pressure drop. The only problem that limits the precision of the final results is the determination of the friction factor, since depending on the model used and the assumed conditions for obtaining the friction factor, it is the degree of precision.

Currently in the literature consulted and available are known more than a dozen expressions for determining the friction factor. A large part of them allow obtaining the friction factor as an explicit variable based on known variables, thus facilitating the calculation and simplifying the analyzes, however they have the disadvantage that their areas of applicability is lower with respect to Coolebrook-White's Equations (1) and that the accuracy of the results is also sacrificed due to having a lower correlation index. Table 2 shows a summary of the most widespread at present in the literature consulted and available.

\subsection{Development of problems type II and III.}

In the problems type II, diameter is given, but the flow rate is unknown. A good assumption for the friction factor in such case is obtained from the fully turbulent flow region for the given roughness. This is true for large Reynolds numbers, which is often the case in practice. After the flow rate is obtained, the friction factor can be corrected with the Moody diagram, Equation (1) or similar from table 2, and the process is repeated until the solution converges (usually, only a few iterations are needed for convergence to three or four digits of precision).

In problems type III, the diameter is not known and therefore the Reynolds number and the relative roughness cannot be calculated. Consequently, calculations are started with the assumption of a pipe diameter. Then the pressure drop calculated for the assumed diameter is compared to the specified pressure drop, and the calculations are repeated with another pipe diameter iteratively until convergence.

To avoid tedious iterations in load loss, flow rate and diameter calculations, Swamee and Jain proposed in 1976 the following explicit relationships, whose use throws average error with respect to the values obtained through the iterative process described in the previous paragraphs.

a) For the problems type 1 (Determining the pressure drop)

The Equation (12) is validate for $3 \cdot 10^{3} \leq \operatorname{Re} \leq 3 \cdot 10^{8}$ and $0,01 \geq e / d \geq 10^{-6}$

In Equation (12) $\mathrm{w}$ is the flow rate, $\mathrm{g}$ is the gravity acceleration, $\mathrm{L}$ is the pipe length, $v$ is the kinematic viscosity. 
Table 2. Somes empirical Equations for the determination of Darcy's friction factor $f$

Author

Alshul(1962)

Equation

Pavlov(1975)

$f=\left[1,8 \log \left(\frac{\operatorname{Re}}{0,135 \operatorname{Re}(e / d)+6,5}\right)\right]^{-2}$

$\frac{1}{\sqrt{f}}=-2 \log \left(\frac{e / d}{3.7}+\left(\frac{6,81}{\operatorname{Re}}\right)^{0,9}\right)$

Swamee-Jain

(1976)

$\frac{1}{\sqrt{f}}=-2 \log \left(\frac{e / d}{3.7}+\frac{5,74}{\operatorname{Re}^{0,9}}\right)$

Halaand (1982) $\frac{1}{\sqrt{f}}=-1,8 \log \left(\left(\frac{e / d}{3.7}\right)^{1,11}+\frac{6,9}{\operatorname{Re}}\right)$

Zigrang (1982) $\quad \frac{1}{\sqrt{f}}=-2 \log \left(\frac{e / d}{3.7}-\frac{5,02}{\operatorname{Re}} \log \left(\frac{e / d}{3.7}+\frac{13}{\operatorname{Re}}\right)\right)$

$$
\frac{1}{\sqrt{f}}=8\left[\left(\frac{8}{\operatorname{Re}}\right)^{12}+\frac{1}{(A+B)^{3 / 2}}\right]^{1 / 12}
$$

Churchill (1973)

$$
A=\left[2,457 \operatorname{Ln}\left(\frac{1}{\left(\frac{7}{\operatorname{Re}}\right)^{0,9}+0,27 e / d}\right)\right]^{16} \quad ; \quad B=\left(\frac{37,53}{\operatorname{Re}}\right)^{16}
$$$$
\frac{1}{\sqrt{f}}=-2 \log \left(\frac{e / d}{3,7}+\frac{4,518 \log \left(\frac{\operatorname{Re}}{7}\right)}{\operatorname{Re}\left(1+\frac{1}{29} \operatorname{Re}^{0,52}(e / d)^{0,7}\right)}\right)
$$$$
f=\frac{0,08(e / d)^{0,225}+0,265(e / d)+66,69(e / d)^{0,4}}{\operatorname{Re}^{N}}
$$$$
N=1,778(e / d)^{0,134}
$$

Madanilli (1981)

$$
f=\left[-2 \log \left(\frac{(e / d)}{3,7}+\frac{95}{\operatorname{Re}^{0,983}}-\frac{96,82}{\operatorname{Re}}\right)\right]^{-2}
$$

$$
f=\left[-2\left(\log \left(\frac{e}{d}-\frac{\psi}{\zeta}\right)-0,568\right)\right]^{-2}
$$

Camaraza et al. (2011)

$$
\begin{aligned}
& \psi=8,49 \log \left[\frac{47,6}{\operatorname{Re}^{2}}+\frac{3,256(e / d)^{1,15}}{\operatorname{Re}}+\frac{(e / d)^{2,2}}{16,598}\right] \\
& \xi=\operatorname{Re}\left[\log \left(\operatorname{Re}^{2,5}(e / d)^{1,1}\right)\right]^{0,01}
\end{aligned}
$$

\section{Validity range}

$4000 \leq \operatorname{Re} \leq 10^{8}$

$0,05 \leq e / d \leq 10^{-6}$

$5000 \leq \operatorname{Re} \leq 10^{8}$

$0,01 \geq e / d \geq 10^{-6}$

$5000 \leq \operatorname{Re} \leq 10^{8}$

$0,01 \geq e / d \geq 10^{-6}$

$5000 \leq \operatorname{Re} \leq 10^{8}$

$0,01 \geq e / d \geq 10^{-6}$

$5000 \leq \operatorname{Re} \leq 10^{8}$

$0,05 \geq e / d \geq 10^{-7}$

$4000 \leq \operatorname{Re} \leq 10^{8}$

$0,05 \geq e / d \geq 10^{-7}$

$4000 \leq \operatorname{Re} \leq 10^{8}$

$0,05 \geq e / d \geq 10^{-7}$

$5000 \leq \operatorname{Re} \leq 10^{8}$

$0,05 \geq e / d \geq 10^{-7}$

$5000 \leq \operatorname{Re} \leq 10^{8}$

$0,05 \geq e / d \geq 10^{-7}$

$4000 \leq \operatorname{Re} \leq 10^{8}$

$0,05 \geq e / d \geq 10^{-7}$

$\Delta p=1,07 \frac{w^{2} L}{g d^{5}}\left\{\operatorname{Ln}\left[\frac{e / d}{3,7}+4,62\left(\frac{v d}{w}\right)^{0,9}\right]\right\}^{-2}$

$$
w=-0,965 d^{2} \sqrt{\frac{g d \Delta p}{L}} \operatorname{Ln}\left[\frac{e / d}{3,7}+\frac{1,784 v}{\sqrt{\frac{g d^{3} \Delta p}{L}}}\right]
$$


Equation (13) is validate for $4 \cdot 10^{3} \leq \operatorname{Re} \leq 10^{8}$ and $0,05 \geq e / d \geq 10^{-7}$. In Equation (13) $\Delta \mathrm{p}$ is the head loss in the duct.

c) For the problems type III (Determining the pipe diameter)

d)

$d=0,66\left[e^{1,25}\left(\frac{L w^{2}}{g \Delta p}\right)^{4,75}+v w^{9,4}\left(\frac{L}{g \Delta p}\right)^{5,2}\right]^{0,04}$

Equation (4) is validate for $3 \cdot 10^{3} \leq \operatorname{Re} \leq 3 \cdot 10^{8}$ and $0,01 \geq e / d \geq 10^{-6}$

Note that in the expression (12); (13) and (14) all quantities are dimensional and the units simplify to the desired unit.

\section{PROPOSED EXPLICIT EQUATIONS}

A data set of 3418 exact values of $d$ was generated by solving numerically the Swamme-Jain Equation (14) for $3 \cdot 10^{3} \leq \operatorname{Re} \leq 3,2 \cdot 10^{8}$. For every value of Reynolds number, $e$ was change in the range $0,05 \geq e / d \geq 10^{-7}$. The previous ranges of $\operatorname{Re}$ and e correspond to $3 \cdot 10^{3} \leq \operatorname{Re} \leq 3 \cdot 10^{8}$ and $0,01 \geq e / d \geq 10^{-6}$. The coefficients for the two Equations presented in this paper were development with the Least Squares Method in tkSolver.

Absolute relative errors were estimated by:

$E=\left|\frac{d-d_{S J}}{d_{S J}}\right|$

where $\mathrm{d}_{\mathrm{SJ}}$ is the diameter value obtained by the Swamme-Jain Equations (12), (13) y (14).

According the authors [19], which is reaffirmed in [20], Equation (14) has an average margin of error of approximately $2 \%$. Recently [Babajimopoulos and Terzidis, 2013] found that the mean error is approximately $2.75 \%$. The authors of this article agree with this criterion when finding a mean error value of Equation (14) equal to $2.8 \%$

The authors got three expressions for the determination of head losses, the flow rate and the diameter calculation, whose use generate a of half error regarding values that were obtained through the iterative process described in previous paragraphs, in addition to possess a more ample specific field. The so-called expressions are:

i) For the problems type 1 (Determining the pressure drop)

$$
\Delta p=\frac{0,25 w^{2} L}{g d^{5}\left\{\log \left[(e / d)^{1,11}+23,155\left(\frac{v d}{w}\right)\right]-0,632\right\}^{2}}
$$

The Equation (15) is validate for $3 \cdot 10^{3} \leq \operatorname{Re} \leq 3 \cdot 10^{8}$ and $0,05 \geq e / d \geq 10^{-6}$ $w=-\sqrt{\frac{4,94 g d^{5} \Delta p}{L}}\left(\log \left[\frac{e}{d}+\sqrt{\frac{43,12 v^{2} L}{g d^{3} \Delta p}}\right]-0,568\right)$

The Equation (16) is validate for $4 \cdot 10^{3} \leq \operatorname{Re} \leq 10^{8}$ and $0,05 \geq e / d \geq 10^{-7}$

k) For the problems type III (Determining the pipe diameter)

$d=\left[\sqrt{\frac{e w^{7,6}}{g^{3,8}}}\left(\frac{0,11 L}{\Delta p}\right)^{1,9}+\frac{v^{0,4} w^{3,76}}{g^{2,08}}\left(\frac{0,13 L}{\Delta p}\right)^{2,08}\right]^{0,1}$

The Equation (17) is validate for $3 \cdot 10^{3} \leq \operatorname{Re} \leq 3,2 \cdot 10^{8}$ and $0,05 \geq e / d \geq 10^{-6}$

Note that in the expression (15); (16) and (17) all quantities are dimensional and the units simplify to the desired unit.

Figure 1 shows the correlation of 2284 experimental points with the obtained Equation (17) to solve problems type III (Determining the pipe diameter) in logarithmic coordinates,

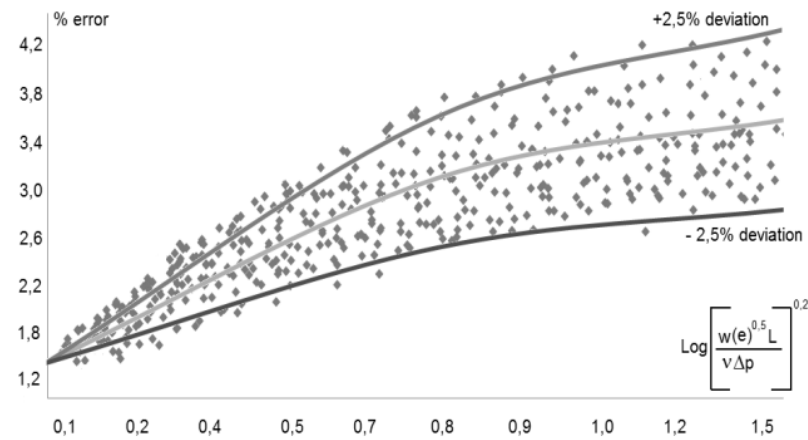

Figure 1. Correlation of 2284 experimental points with the Equation (17)

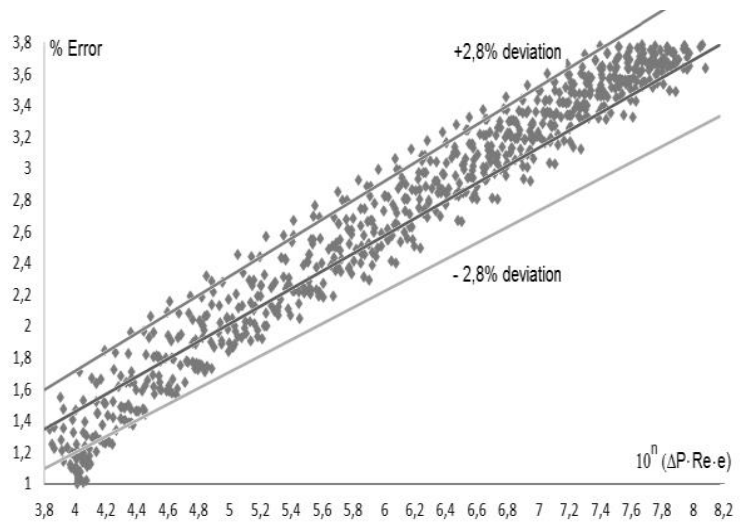

Figure 2. Correlation enter adimensional Reynold's number and medium error obtained with the uses of Equation (16)

In the figure 2 is shown the correlation between dimensionless Reynold's number and the medium error obtained when using Equation (16) was made a comment beforehand about the divergence among these models is little, but the question arises as to which of these models best represents the experimental data that originated or was used for its validation.

The calculation of the relative error when validating Swamee -Jain's Equation (14) is shown in figure 3. The 
analysis made to this Equation evidences a maximum error equal to $3,8 \%$, while experimental available data correlate with a $\pm 2.8 \%$ in $82.4 \%$ of the experimental points.

The calculation of the error relative when validating Equation (17) is shown in figure 4. The analysis made to this Equation evidences a maximum error equal to $3.92 \%$, while experimental available data correlate with a $\pm 2.5 \%$ in $88,1 \%$ of the experimental points. It can be verified that the Equation (17) provides results that are closer to the available experimental data, so it is considered to be more accurate, besides having a more specific field.

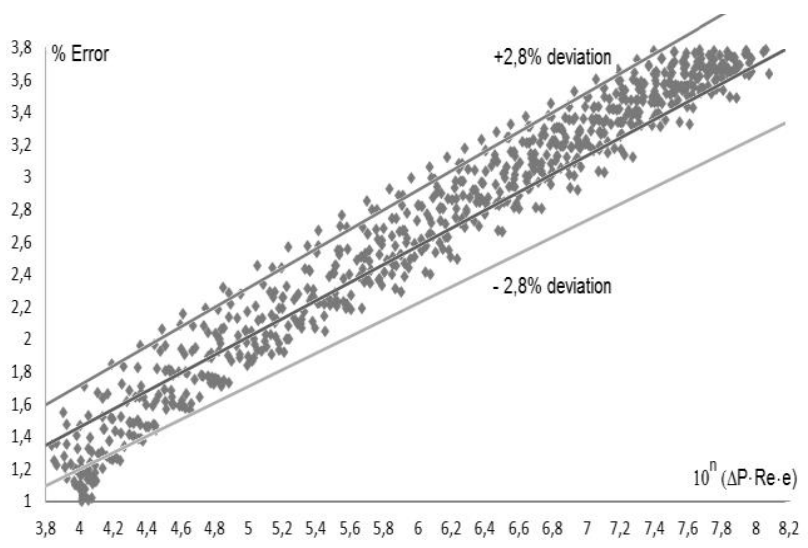

Figure 3. Correlation of experimental data with Swamee-Jain Equation (14)

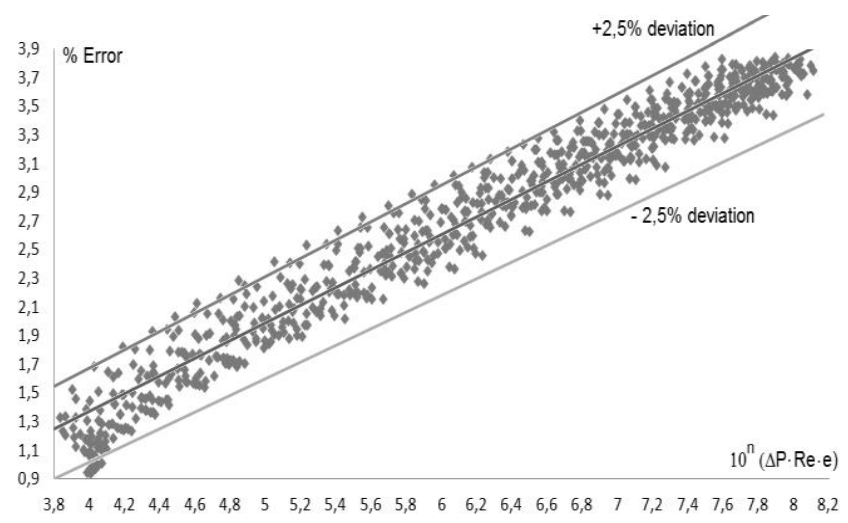

Figure 4. Correlation of experimental data with Equation

By the results obtained, the Equation (17) shows with an average error value of the order of $2,5 \%$, which is lower than the $2,8 \%$ error obtained by using Equation (14). Another aspect of interest is the fact that the experimental data used in the validation of the models fit better to Equation (17) than to expression (14), these reasons are solid elements by which the authors of this article recommend the expression (17) for the evaluation of piping systems, considering it accurate and reliable.

\section{CONCLUSIONS}

An explicit model was obtained to determine the diameter of a duct, using a regression, with the best possible adjustment to the experimental data that gave rise to it and better than the best recognized model, the Swamee - Jain Equation. The new Equation obtained allows to reach a greater precision, facilitates the engineering calculations, besides extending the domain of applicability of the same ones to possess a zone of validation more extensive, so that its work is recommended in process of engineering calculations.

The mathematical performance of the explicit proposed model is:

$d=\left[\sqrt{\frac{e w^{7,6}}{g^{3,8}}}\left(\frac{0,11 L}{\Delta p}\right)^{1,9}+\frac{v^{0,4} w^{3,76}}{g^{2,08}}\left(\frac{0,13 L}{\Delta p}\right)^{2,08}\right]^{0,1}$

Validate for $3 \cdot 10^{3} \leq \operatorname{Re} \leq 3,2 \cdot 10^{8}$ and $0,05 \geq e / d \geq 10^{-6}$

The analysis made to this Equation evidences a maximum error equal to $3,92 \%$, while experimental available data correlate with a $\pm 2,5 \%$ in $88,1 \%$ of the experimental points. It can be verified that the Equation (8) provides results that are closer to the available experimental data, so it is considered to be more accurate, besides having a more specific field.

\section{ACKNOWLEDGMENT}

This work was supported by Doctoral Research Program of Universidad Central de las Villas, Cuba.

\section{REFERENCES}

[1] Giustolisi O., Berardi L., Walski T.M. (2011). Some explicit formulations of Colebrook-White friction factor considering accuracy vs. computational speed, Journal of Hydroinformatics, Vol. 13, No. 3, pp. 401418.

[2] Bombardelli F., Garcia M. (2003). Hydraulic design of large-diameter pipes, J.Hydraul.Eng., Vol. 129, No. 11, pp. 839-846.

[3] Brkić D. (2011a). New explicit correlations for turbulent flow friction factor, Nucl.Eng.Des., Vol. 241, No. 9, pp. 4055-4059.

[4] Brkić D. (2011b). Review of explicit approximations to the Colebrook relation for flow friction, Journal of Petroleum Science and Engineering, Vol. 77, No. 1, pp. 34-48.

[5] Clamond D. (2009). Efficient resolution of the Colebrook equation, Ind Eng Chem Res, Vol. 48, No. 7, pp. 3665-3671.

[6] Camaraza Y. el at., (2010), Ecuación explícita para el cálculo de factores de fricción en la zona de transición del régimen turbulento, Tecnología Química, Vol. 30, No. 1, pp. 76-83.

[7] Colebrook C.F. (1939). Turbulent flow in Pipes, with reference to the transition region between the smooth and rough pipe laws, J. Inst. Civil Eng, Vol. 11, No. 4, pp. 133-156.

[8] Danish M., Kumar S., Kumar S. (2011). Approximate explicit analytical expressions of friction factor for flow of Bingham fluids in smooth pipes using Adomian decomposition method, Communications in Nonlinear Science and Numerical Simulation, Vol. 16, No. 1, pp. 239-251.

[9] Diniz V.E. M.G., Souza P.A. (2009). Four explicit formulae for friction factor calculation in pipe flow, 
Transactions on Ecology and the Environment, Vol. 125, pp. 369-380.

[10] Fang X., Xu Y., Zhou Z. (2011). New correlations of single-phase friction factor for turbulent pipe flow and evaluation of existing single-phase friction factor correlations, Nucl.Eng.Des, Vol. 241, No. 3, pp. 897902.

[11] Barr D.I.H. (1977). Discussion on accurate explicit equations for friction factor, J. Hydraul. Div. Am. Soc. Civ. Eng., Vol. 103, No. 3, pp. 334-337.

[12] Gulyani B.B. (2001). Approximating equations for pipe sizing, Chemical Engineering, Vol. 108, No. 2, pp. 105108.

[13] Imbrahim C. (2005). Simplified equations calculate head losses in comercial pipes, The Journal of American Science, Vol. 1, No. 1, pp. 1-2.

[14] Haaland S.E. (1983). Simple and explicit formulas for the friction factor in turbulent pipe flow, J.Fluids Eng., Vol. 105, No. 1, pp. 89-90.
[15] Jain K. (1976). Accurate explicit equation for friction factor, Journal of Hydraulics Division, ASCE, Vol. 102, pp. 674-677.

[16] Li P., Seem J.E., Li Y. (2011). A new explicit Equation for accurate friction factor calculation of smooth pipes, Int.J.Refrig., Vol. 34, No. 6, pp. 1535-1541.

[17] Romeo E., Royo C., Monzón A. (2002). Improved explicit equations for estimation of the friction factor in rough and smooth pipes., Chem.Eng.J., Vol. 86, No. 3, pp. 369-374.

[18] Sonnad J., Goudar C. (2006). Turbulent flow friction factor calculation using a mathematically exact alternative to the colebrook-White equation., J.Hydraul.Eng., Vol. 132, No. 8, pp. 863-867.

[19] Swamee P.K., Jain A.K. (1976). Explicit equations for pipe flow problems, J.Hydraul.Eng. ASCE, Vol. 102, No. 5, pp. 657-664.

[20] Swamee P.K., Rathie P.N. (2007). Exact equations for pipe-flow problems, Journal of Hydraulic Research, Vol. 45, No. 1, pp. 131-134. 